\title{
Age and sex differences in emergency department visits of nursing home residents: a systematic review
}

\author{
Annika Brucksch ${ }^{1}$, Falk Hoffmann ${ }^{2}$ and Katharina Allers ${ }^{2^{*}}$ (D)
}

\begin{abstract}
Background: Nursing home residents (NHRs) are often transferred to emergency departments (EDs). A great proportion of ED visits is considered inappropriate. There is evidence that male NHRs are more often hospitalised, but this is less clear for ED visits. It is unclear, which influence age has on ED visits. We aimed to study the epidemiology of ED visits in NHRs focusing on age- and sex-specific differences.

Methods: A systematic review was carried out based on articles found in MEDLINE (via PubMed), CINAHL and Scopus. Articles published on or before Aug 31, 2017 were eligible. Two reviewers independently identified articles for inclusion. The quality of studies was assessed by the Joanna Briggs Institute critical appraisal tool for prevalence studies.
\end{abstract}

Results: Out of 1192 references, we found seven studies meeting our inclusion criteria. Six studies were conducted in the USA or Canada. Overall, 29-62\% of NHRs had at least one ED visit over the course of 1 year. Most studies assessing the influence of sex found that male residents visited EDs more frequently. All but one of the five studies with multivariable analyses reported a statistically significant positive association (with odds or rate ratios of 1.05-1.38). All studies assessed the influence of age. There was no clear pattern with some studies showing no association between ED visits and age and other studies reporting decreasing ED visits with increasing age or increasing proportions followed by a decrease in the highest age group. Studies used $85+$ or $86+$ years as the highest age category. Hospital admission rate ranged from 36.4 to $48.7 \%$. There was no study reporting stratified analyses by age and sex. Only one study reported main diagnoses leading to ED visits stratified by sex.

Conclusion: Male NHRs visit EDs more often than females, but there is no evidence on reasons. The association with age is unclear. Any future study on acute care of NHRs should assess the influence of age and sex. These studies should include large sample sizes to provide a more differentiated age categorisation.

Trial registration: PROSPERO CRD42017074845.

Keywords: Nursing, Nursing home (NH), Nursing home resident (NHR), Emergency department (ED), ED visit, Age, Sex, Hospital admission

\footnotetext{
* Correspondence: katharina.allers@uni-oldenburg.de

${ }^{2}$ Department of Health Services Research, Carl von Ossietzky University

Oldenburg, Oldenburg, Germany

Full list of author information is available at the end of the article
}

(c) The Author(s). 2018 Open Access This article is distributed under the terms of the Creative Commons Attribution 4.0 International License (http://creativecommons.org/licenses/by/4.0/), which permits unrestricted use, distribution, and reproduction in any medium, provided you give appropriate credit to the original author(s) and the source, provide a link to the Creative Commons license, and indicate if changes were made. The Creative Commons Public Domain Dedication waiver (http://creativecommons.org/publicdomain/zero/1.0/) applies to the data made available in this article, unless otherwise stated. 


\section{Background}

Older people use emergency department (ED) services more often than persons of younger age [1]. In times of demographic changes, the burden on ED systems may further increase. In 2014, just over 1.4 million residents were living in US nursing homes, corresponding to $2.6 \%$ of the over-65 population and $9.5 \%$ of the over- 85 population [2]. Compared with community dwellers nursing home residents (NHRs) have higher utilisation rates of EDs [3]. However, a large proportion of these ED presentations is considered inappropriate $[4,5]$. Furthermore, it is questionable if benefits outweigh potential risks as ED visits of NHRs often result in unintended consequences and adverse outcomes like greater cognitive and physical decline or hospital-acquired infections $[6,7]$. Approximately $50 \%$ of NHRs visiting EDs are discharged back to the nursing home without being hospitalised $[8,9]$ and almost one fifth of presentations followed by ED discharge had no diagnostic testing at all [9].

Although NHRs are typically older than 65 years, they represent a wide range of age groups up to over 100 years and a large proportion is female with increasing tendency in older age groups $[10,11]$. Patterns of chronic diseases differ between sexes and across the age span in this population $[10,12]$, but most studies present epidemiologic measures aggregated for both sexes and potential differences between age groups are often not further examined. In their systematic review published in 2011, Gruneir et al. compared ED use by older adults to younger age groups, but they did not report on further age differences in NHRs [1]. Overall, the literature on age differences in hospitalisations of NHRs is inconclusive [13]. This seems also to be the case for ED visits with studies showing different findings $[14,15]$. On the other hand, previous research showed that male NHRs are more often hospitalised than female NHRs [13, 16, 17], which might also apply for ED visits $[15,18]$.

The aim of this systematic review is to estimate the incidence and prevalence of ED visits in NHRs, focusing on age-specific and sex-specific patterns. We also gathered information on age-specific and sex-specific differences in reasons for ED visits, revisits and hospital admissions.

\section{Methods}

A protocol of this systematic review was registered with PROSPERO (http://www.crd.york.ac.uk/PROSPERO; No.: CRD42017074845).

A systematic literature search was carried out for articles published on or before Aug 31, 2017. In a first step electronic databases including MEDLINE (via PubMed), CINAHL and Scopus were searched combining an adapted version of the search strategy of Hoffmann and Allers for NHRs [13] and a filter to retrieve studies related to EDs from Kung and Campbell [19]. The search strategy can be found in the Additional file 1. In a second step the reference lists of all identified articles were scanned for additional studies. There was no limitation regarding the time period.

\section{Inclusion and exclusion criteria}

Studies were included if they assessed all-cause ED visits among NHRs and presented age-specific or sex-specific analyses on incidence or prevalence of ED visits or included one of these variables in crude or multivariable regression models.

Prevalence is defined as the proportion of NHRs admitted to EDs at a given point in time. Numerator is the total number of NHRs admitted to EDs and denominator is the total number of NHRs.

Incidence is defined as the measure of ED visits within a specified period of time and is usually expressed as a rate (e.g. per 100 or 1000 resident days, resident years, nursing home bed days). Numerator is NHRs' ED visits and denominator is either the total number of NHRs under risk within a specified period of time or the accumulated time NHRs are at risk.

ED is defined as a hospital facility that provides unscheduled outpatient services to patients whose conditions require immediate care because of injury or illness or urgent medical conditions, and is staffed $24 \mathrm{~h}$ a day [20].

The current review considered prevalence studies, prospective and retrospective cohort studies and (randomised) controlled trials (provided that data from the comparison group were reported) for inclusion. There were no language restrictions and all articles published in languages other than English were translated.

Studies were excluded if they were restricted to specific groups of NHRs (e.g. specific diagnoses, specific levels of care, only NHRs with previous ED visits) or specific ED visits (e.g. specific diagnoses, only ED visits leading to hospitalisation).

\section{Study selection and data extraction}

After removing duplicates, all titles and abstracts were screened independently by two reviewers ( $A B$ and $K A$ ) against the predefined inclusion criteria. In a next step, the full texts of all potentially relevant articles were assessed by the same reviewers. Any disagreement was resolved by discussion or by involving a third reviewer $(\mathrm{FH})$. Data extraction was performed by one reviewer $(\mathrm{AB})$ and verified by a second (KA).

We performed a descriptive synthesis of the identified studies due to the heterogeneity of the included studies.

\section{Risk of bias/quality assessment}

All included studies were assessed by two independent reviewers ( $\mathrm{AB}$ and $\mathrm{KA}$ ) for methodological validity using 
a version of the prevalence critical appraisal instrument from the Joanna Briggs Institute (JBI) [21]. Any disagreements that arose between the reviewers were resolved by discussion or by a third reviewer (FH). We considered every study that met the inclusion criteria independent of their quality.

\section{Results}

\section{Search results}

After the removal of duplicates electronic searches identified a total of 1192 records. Screening for titles and abstracts resulted in the exclusion of 1095 records. Ninety-seven of the remaining potentially relevant articles were obtained in full text including four French, two Spanish, one Russian and one Hebrew article. Full text screening resulted in the exclusion of 90 articles and a total of seven articles were eligible for inclusion. No further articles were found in reference lists of the identified articles (Fig. 1).

\section{Study characteristics}

The included studies were from the USA $(n=5)[15,22-25]$, Sweden $(n=1)$ [14] and Canada $(n=1)$ [18]. The years of data used ranged from 1995 to 2009. Articles were published from 1998 to 2016. The studies included data from 719 to 132,753 NHRs. Follow-up periods ranged from 1 month to 3 years. Data on ED visits were most commonly obtained from administrative data or Minimum Data Set $(n=4)$ [22-25]. In the other three studies, data were collected by hospital staff $[15,18]$ or registered nurses [14]. The two articles from Stephens et al. reported findings from the same study but used different designs, analyses and number of participants [24, 25]. Therefore, both articles were included (Table 1).

\section{Quality appraisal of included studies}

The quality assessment of all included studies and quality criteria are given in Table 2 . The percentage of quality criteria answered with 'Yes' varied between 88 and $100 \%$. The sample was representative of the target population in all studies. All study participants were recruited in an appropriate way and all studies used objective criteria assessing ED visits. All studies except one used appropriate statistical analyses. Overall, questions were answered predominantly with 'Yes', because almost all studies used administrative data. The remaining two studies

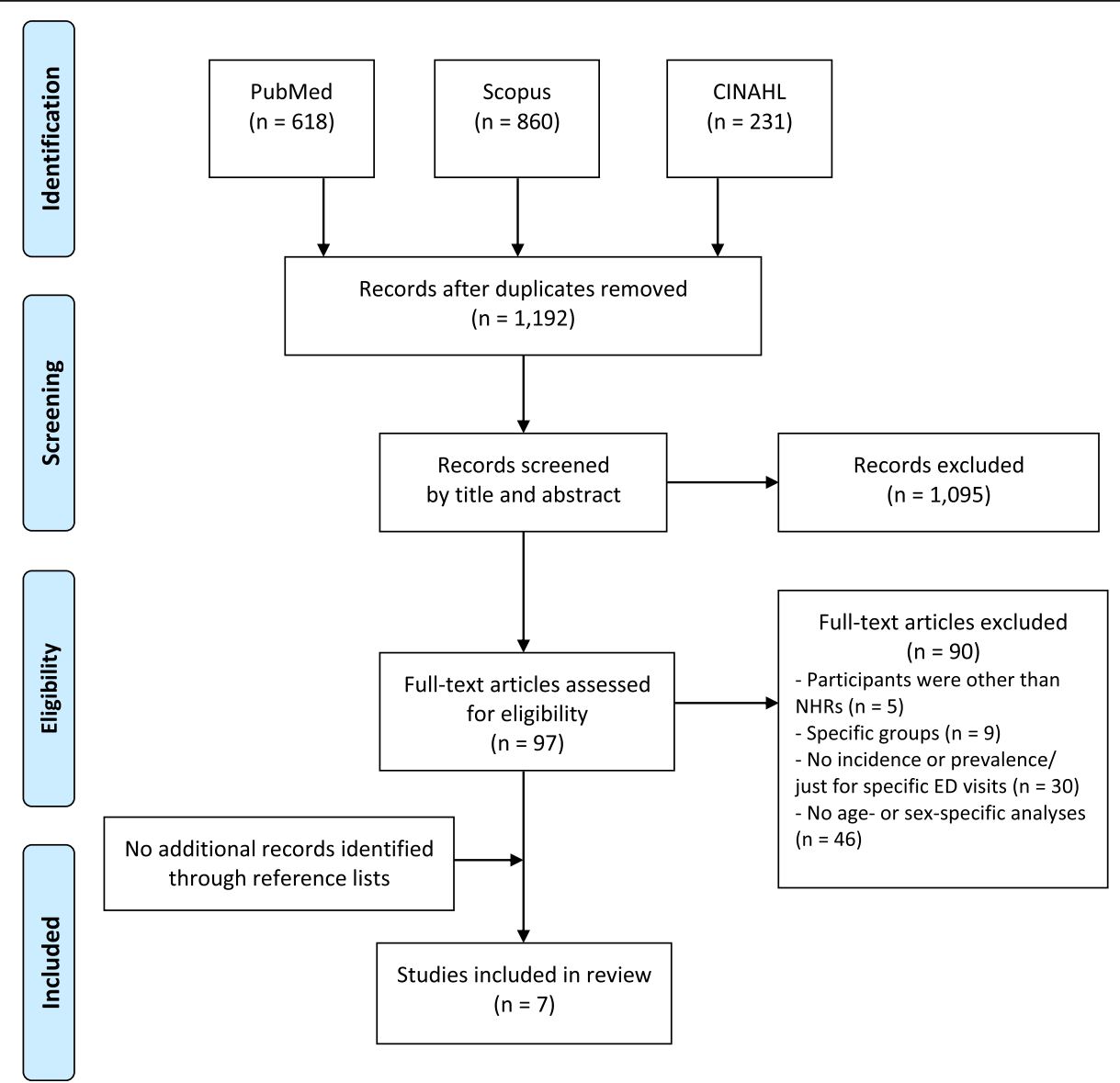

Fig. 1 Flowchart of the literature search 
Table 1 Characteristics of included studies

\begin{tabular}{|c|c|c|c|c|c|}
\hline Author (year) & Country of origin & Study design (data source) & Year of data & Sample & $\begin{array}{l}\text { Mean age of residents } \\
\text { (\% female) }\end{array}$ \\
\hline $\begin{array}{l}\text { Ackermann et al. } \\
\text { (1998) [22] }\end{array}$ & USA & $\begin{array}{l}\text { Retrospective chart review (ED } \\
\text { records and data from the } 1995 \\
\text { State of Georgia Annual Nursing } \\
\text { Home Questionnaire) }\end{array}$ & 1995 & $\begin{array}{l}10 \mathrm{NHs} \text { with } 1300 \text { beds and } 4 \\
\text { hospital-based EDs }\end{array}$ & $\begin{array}{l}65-74 \text { years: } 20.7 \%^{\mathrm{a}} \\
75-84 \text { years: } 34.3 \%^{\mathrm{a}} \\
85+\text { years: } 29.0 \% \\
(67.4 \%)\end{array}$ \\
\hline $\begin{array}{l}\text { Hsiao and Hing } \\
\text { (2014) [15] }\end{array}$ & USA & $\begin{array}{l}\text { Cross-sectional study (data from } \\
\text { the ED component of the } \\
2001-2008 \text { National Hospital } \\
\text { Ambulatory Medical Care Survey } \\
\text { (NHAMCS)) }\end{array}$ & $2001-2008$ & $\begin{array}{l}\text { NHRs } \geq 65 \text { years (no sample size } \\
\text { given) }\end{array}$ & No data available \\
\hline $\begin{array}{l}\text { Kihlgren et al. } \\
\text { (2014) [14] }\end{array}$ & Sweden & $\begin{array}{l}\text { Cross-sectional follow-up study } \\
\text { (RN's documentation + Residents } \\
\text { Assessment Instrument/Minimum } \\
\text { Data Set (MDS)) }\end{array}$ & 2000-2002 & $\begin{array}{l}719 \text { NHRs } \geq 75 \text { years from } 24 \\
\text { NHs }\end{array}$ & $\varnothing 85.8$ years $(71.0 \%)$ \\
\hline $\begin{array}{l}\text { LaMantia et al. } \\
\text { (2016) [23] }\end{array}$ & USA & $\begin{array}{l}\text { Retrospective cohort study } \\
\text { (merged data set of Medicare } \\
\text { and Medicaid claims and } \\
\text { resident-level Minimum Data Set } \\
\text { (MDS)) }\end{array}$ & 1999-2009 & 4491 long-stay NHRs $\geq 65$ years & $\varnothing 79.6$ years $(66.2 \%)^{a}$ \\
\hline $\begin{array}{l}\text { McGregor et al. } \\
\text { (2014) [18] }\end{array}$ & Canada & $\begin{array}{l}\text { Retrospective cohort study } \\
\text { (secondary administrative data } \\
\text { on NHRs and ED records) }\end{array}$ & 2005-2008 & $\begin{array}{l}13,140 \mathrm{NHRs} \text { from } 48 \text { publicly } \\
\text { funded } \mathrm{NHs}\end{array}$ & $\varnothing 83.1$ years (66.6\%) \\
\hline $\begin{array}{l}\text { Stephens et al. } \\
\text { (2012) [24] }\end{array}$ & USA & $\begin{array}{l}\text { Cross-sectional study (NH } \\
\text { resident assessment data/ } \\
\text { Minimum Data Set (MDS) and } \\
\text { Centers for Medicare and } \\
\text { Medicaid Services (CMS) } \\
\text { administrative claims) }\end{array}$ & 2006 & $\begin{array}{l}132,753 \text { NHRs } \geq 65 \text { years from } \\
2006 \text { national random sample }\end{array}$ & $\begin{array}{l}65-75 \text { years: } 19.5 \% \\
76-85 \text { years: } 41.2 \% \\
86+\text { years: } 39.3 \% \\
(68.7 \%)^{\mathrm{a}}\end{array}$ \\
\hline $\begin{array}{l}\text { Stephens et al. } \\
\text { (2014) [25] }\end{array}$ & USA & $\begin{array}{l}\text { Retrospective cohort study } \\
\text { (Medicare administrative claims } \\
\text { and NH resident assessment } \\
\text { data/Minimum Data Set (MDS)) }\end{array}$ & 2006 & $\begin{array}{l}112,421 \mathrm{NHRs} \geq 65 \text { years from } \\
2006 \text { national sample }\end{array}$ & $\begin{array}{l}65-75 \text { years: } 19.6 \% \\
76-85 \text { years: } 41.0 \% \\
86+\text { years: } 39.4 \% \\
(68.9 \%)\end{array}$ \\
\hline
\end{tabular}

$\mathrm{NH}$, nursing home; $\varnothing$, mean; ED, emergency department; RN, registered nurses

The Minimum Data Set (MDS) is part of the federally mandated process for clinical assessment of all residents in Medicare and Medicaid certified nursing homes

${ }^{a}$ Calculated from data given in the publication

${ }^{\mathrm{b}}$ These articles used the same data set

Table 2 Summary of quality assessment

\begin{tabular}{|c|c|c|c|c|c|c|c|c|c|}
\hline Author (year) & 1 & 2 & 3 & 4 & 5 & 6 & 7 & 8 & 9 \\
\hline Ackermann et al. (1998) [22] & Yes & Yes & Yes & Yes & Not applicable & Yes & Yes & No & Yes \\
\hline Hsiao and Hing (2014) [15] & Yes & Yes & Yes & Yes & Not clear & Yes & Yes & Yes & Yes \\
\hline Kihlgren (2014) [14] & Yes & Yes & Yes & Yes & Not clear & Yes & Yes & Yes & Yes \\
\hline LaMantia et al. (2016) [23] & Yes & Yes & Yes & Yes & Not applicable & Yes & Yes & Yes & Yes \\
\hline McGregor et al. (2014) [18] & Yes & Yes & Yes & Yes & Not applicable & Yes & Yes & Yes & Yes \\
\hline Stephens et al. (2012) [24] & Yes & Yes & Yes & Yes & Not applicable & Yes & Yes & Yes & Yes \\
\hline Stephens et al. (2014) [25] & Yes & Yes & Yes & Yes & Not applicable & Yes & Yes & Yes & Yes \\
\hline
\end{tabular}

Quality appraisal criteria [21]:

1. Was the sample frame appropriate to address the target population?

2. Were study participants sampled in an appropriate way?

3. Was the sample size adequate?

4. Were the study subjects and setting described in detail?

5. Was the data analysis conducted with sufficient coverage of the identified sample?

6. Were valid methods used for the identification of the condition?

7. Was the condition measured in a standard, reliable way for all participants?

8. Was there appropriate statistical analysis?

9. Was the response rate adequate, and if not, was the low response rate managed appropriately? 
including one survey mentioned the response, but gave no details regarding a sufficient coverage of the identified sample.

\section{Resident characteristics}

Studies commonly included all residents $(n=2)[20,24]$ or all residents aged 65 and older $(n=4)$ [15, 23-25]. One study included only residents aged 75 and older [14]. Two studies investigated residents with varying stages of cognitive impairment and dementia [23, 25]. The mean age of NHRs ranged from 79.6 to 85.8 years $[14,18,23]$ and between $29.0-39.4 \%$ were aged 85 or 86 years and older [22, 24, 25]. In these six studies between 66.2 and $71.0 \%$ were females. In one study [15] baseline data on age and sex were not reported.

\section{Frequency of ED visits}

All but one study [25] examined some measure of all-cause ED visits (Table 3). The proportion of NHRs admitted to the ED ranged from 29 to $62 \%$ over a one-year period [14, 23, 24]. The incidence of ED visits ranged between 62.6 and 215.5 per 100 resident years $[14,15,18,22,23]$, with three of the studies ranging between 110 and $150 \mathrm{ED}$ visits per 100 resident years $[14,15,22]$. One study found a trend towards increasing ED visits over time with a rate of 146.0 ED visits per 100 resident years in 2001 compared to 215.5 ED visits per 100 resident years in 2008 [23].

All studies assessed the influence of sex. Two studies stratified their results for males and females $[14,15]$ and four studies conducted regression analyses including sex in the model $[18,22,23,25]$. One study reported both [24]. Most studies came to the conclusion that male NHRs visit EDs more often than females. One study reported that $65.3 \%$ of the male NHRs visited the ED over a one-year period compared to $60.5 \%$ of the female NHRs [24], while another study reported a prevalence of 33 and $28 \%$ for male and female NHRs [14], respectively. A further study found an incidence of 154.5 per 100 resident years for male and 111.6 per 100 resident years for female NHRs [15]. All but one of the multivariable analyses reported a statistically significant positive association between male sex and ED visits (odds or rate ratio: $1.05-1.38)$ [18, 22, 24, 25]. The other study analysed factors predicting time to first ED visit in the year after study entry and found no association between male sex and ED visits [23].

All seven studies assessed the influence of age. Three of the studies stratified their results by age [14, 15, 24]. One study reported decreasing incidences of ED visits with rising age (65-74 years: 153.2, 75-84 years: 124.3, 85+ years: 113.0 ED visits per 100 resident years) [17]. Another study found a higher prevalence of ED visits (30\%) in the age of 85 years and older compared to the age of $75-84$ years $(25 \%)$, but this finding was not statistically significant [14]. The third study underlined a slightly increasing prevalence of ED visits from 65-75 years (62.7\%) to $76-85$ years $(63.9 \%)$ of age and a slightly decreasing proportion in those aged 86 years and older (59.7\%) [24]. Five studies included age in regression analyses [18, 22-25]. Whereas Stephens et al. found significantly lower odds of any ED visit for the age of 65-75 years compared to the age of 76-85 years, this was not statistically significant for the age group of 85 years and older [24]. One study found that higher age was associated with lower rates of total ED visits [25], while two other studies did not show any association between age and overall ED use rate [18, 22]. One study found that age influences the time to first ED visit [23]. However, of the five studies that conducted multivariable analyses, only two used the same age categories (65$75,76-85$ and $86+$ years) $[24,25]$, two incorporated age as a continuous variable $[18,23]$, and the last did not clearly report how age was included in the model, but probably also continuously [22].

\section{Reasons for ED visits}

Of the seven included studies, one reported diagnoses for ambulatory care sensitive conditions (ACSC), which made up 14.6\% of all ED transfers. The two most common diagnoses were kidney/urinary tract infection (4.9\%) and congestive heart failure (3.2\%) [15]. Two further studies gave reasons for all ED transfers [14, 22]. Most common reasons were respiratory symptoms (14.4\%), altered mental status $(10.1 \%)$, gastrointestinal symptoms $(9.9 \%)$ and falls (8.2\%) in the study of Ackermann et al. [22]. Kihlgren et al. reported falls $(22.6 \%)$, cardiovascular and cerebrovascular problems (16.2\%), gastrointestinal symptoms (11.8\%), fever and infections (11.1\%) as the most common reasons [14]. However, with $20.7 \%$ the number of missings on reasons for referrals was high.

One of these two studies reported reasons leading to ED visits stratified by sex [14]. For women, falls were the most frequent reason $(25.4 \%)$ followed by cardiovascular and cerebrovascular problems (15.4\%) and for men falls as well as cardiovascular and cerebrovascular problems $(17.7 \%$ each) were most common. No study stratified reasons for ED visits by age or ACSC diagnoses by sex or age.

One study reported that $23.8 \%$ of NHRs $(24.7 \%$ of male and $23.4 \%$ of female NHRs) had at least one potentially preventable ED visit [24]. The authors also reported slightly decreasing proportions having at least one avoidable ED visit with increasing age (65-75 years: $26.0 \%, 76-85$ years: $24.7 \%$ and $86+$ years: $21.7 \%)$.

\section{Revisits}

Another three studies showed the following pattern of ED revisits. One study reported that $60.5 \%$ had one ED visit, $22.3 \%$ had two visits and $17.2 \%$ had three or more 


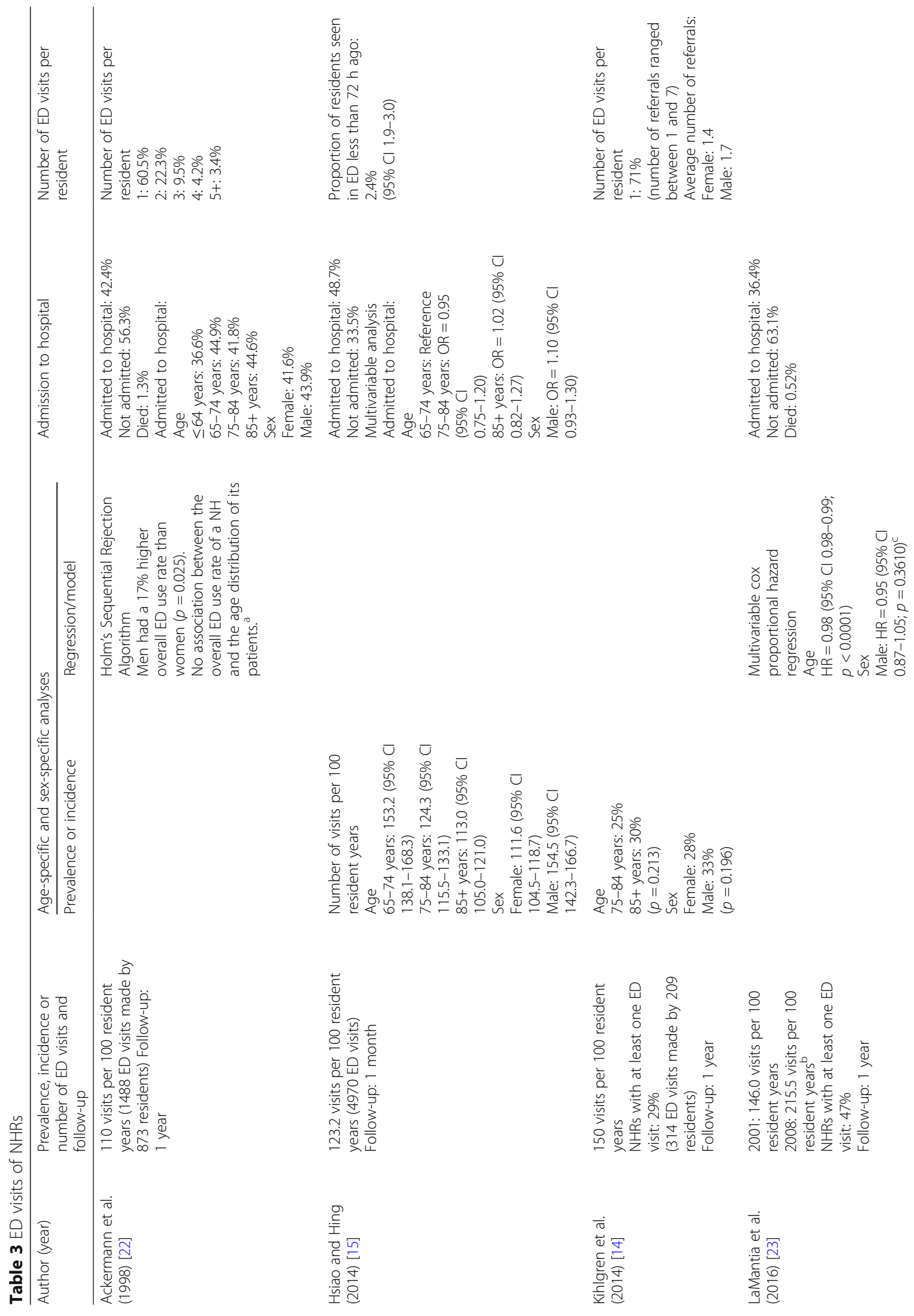




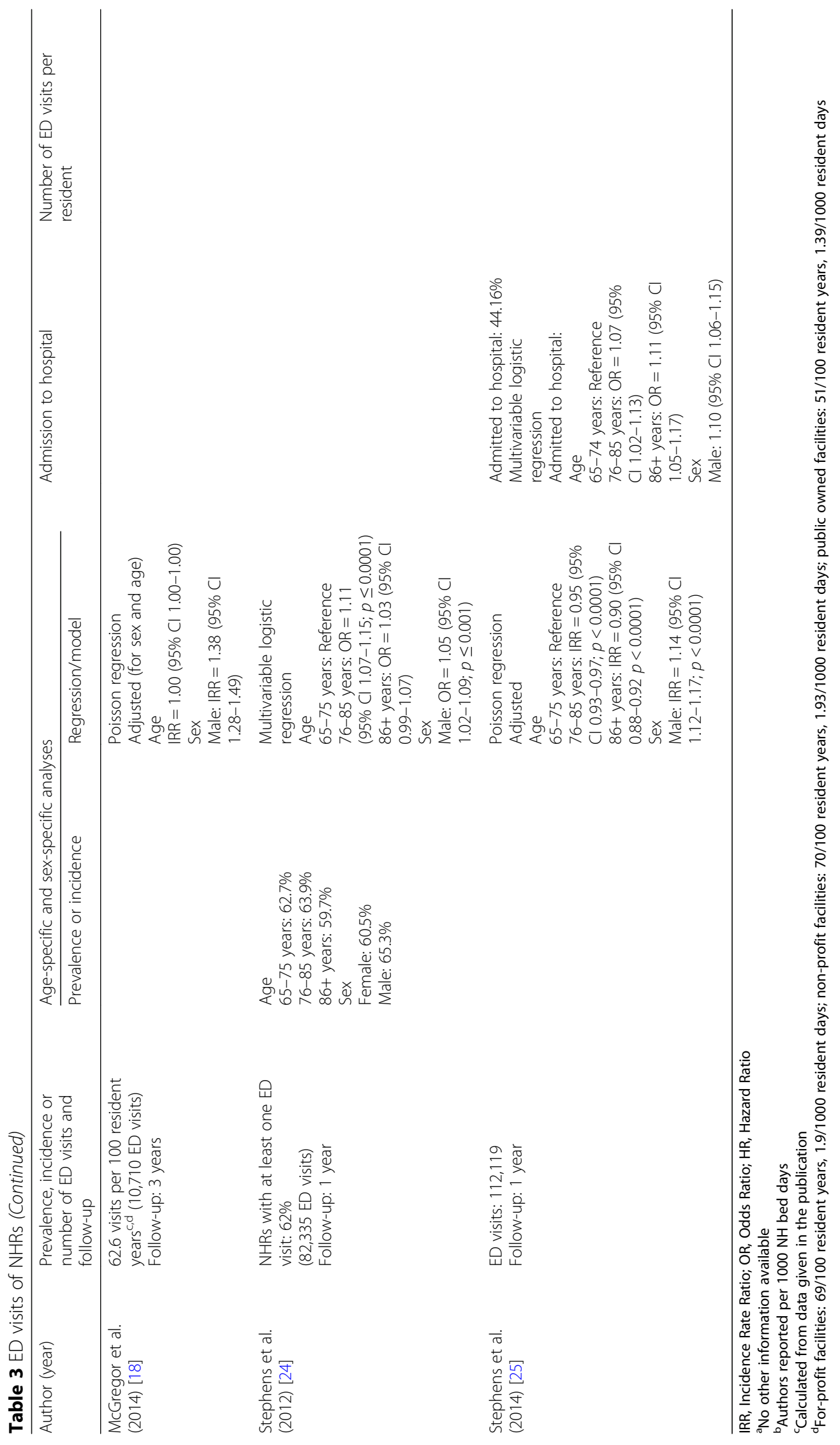


visits over the course of 1 year [22]. The second study found that $2.4 \%$ of the study population had been seen in ED less than $72 \mathrm{~h}$ ago, while $87.3 \%$ were not seen again (for $10.3 \%$ the status was unknown) [15]. Only one study stratified the results by sex, showing that female NHRs had 1.4 revisits and male NHRs 1.7 revisits during the one-year study period [14]. There was no study that stratified revisits by age (Table 3 ).

\section{Hospital admission}

Four studies reported subsequent hospital admissions of NHRs following ED visits. The proportion of hospitalisation ranged from 36.4 to $48.7 \%$ [15, 22, 23, 25] and between 0.5 and $1.3 \%$ of NHRs died in the ED [22, 23]. Three studies $[15,22,25]$ reported on differences of age and sex. While two studies found that patients admitted to hospital did not vary by age and sex [15, 22], one other study reported that male sex and advanced age were associated with higher odds of hospitalisation [25] (Table 3).

\section{Discussion}

\section{Summary of main findings}

This systematic review analysed age-related and sex-related ED presentations in NHRs and found only very few studies assessing these patterns. Most studies examining sex differences in ED visits found that male NHRs visited EDs more often than females. The influence of age was less clear with some studies showing no association and others reporting decreasing ED visits with increasing age or increasing proportions followed by a decrease in the highest age group. However, comparability is limited as some of the included studies used age as a continuous variable. There was no study which reported stratified analyses by age and sex.

\section{Comparison with the existing literature}

We found a wide range between 29 and $62 \%$ of NHRs that had at least one ED presentation over a one-year period and the proportion of NHRs being admitted to hospital ranged from 36.4 to $48.7 \%$. These findings and the variability are comparable with the literature and might also reflect facility-level variations $[1,4,6,9]$. Furthermore, the existing literature is also heterogeneous with respect to methods, time periods and populations. This is important to keep in mind, when comparing and interpreting findings between different studies.

Like in our recent review on hospitalisations of NHRs [13], we also found that male NHRs visited EDs more often than females in this systematic review. We only included studies assessing all NHRs in the denominator instead of only ED patients, because the latter might have led to the conclusion that women visit EDs more frequently $[9,26]$. However, this is explained by the fact that a large proportion of NHRs is female. Although not all included studies found statistically significant effects, which might also be due to small sample sizes, a clear trend was seen. The strongest influence of male sex with a rate ratio of 1.38 was shown by McGregor et al. [18], but this result was not further discussed by the authors as these differences were not the focus of their study. This was also the case in the other included studies. In their review on trends and appropriateness of ED use by older adults, Gruneir et al. [1] did not even mention sex as a potential factor. This was also the case in a more recent review by Trahan et al. on factors influencing decision-making on transitions of NHRs to EDs [27]. Although the authors identified residents and family factors as one of five categories, no sociodemographic factors were considered. Because hospital as well as ED use is higher for males, decisions to transfer seem to be made in the nursing home. Only one of the included studies reported reasons leading to ED visits stratified by sex and found that falls were more often the reason to transfer female NHRs (25.4\% vs. $17.7 \%)$ with men having slightly higher proportions in several other categories [14]. But for one fifth of transfers no reason for referral was available. The proportion of potentially avoidable ED visits was high and ranged between 25 and 55\% $[6,28,29]$. One of our included studies stratified the proportion of NHRs having at least one potentially avoidable ED visit by sex and found only marginal differences between males and females [24]. Furthermore, facility-level variation across nursing homes has been shown to influence health care including ED transfers $[4,30]$, but it is unclear whether sex differences also depend on facility-levels. Future studies should assess which ED transfers vary between sexes.

On the other hand, the influence of age on ED visits was inconsistent in the included studies. There is some evidence of a decreasing influence of age above about 85 years, but this was not shown or assessed in all studies. Such heterogeneous findings were also found in the literature on ED use of elderly patients irrespective of nursing home stay [20, 26, 31, 32]. In our systematic review on hospitalisations of NHRs we also concluded that the influence of age was inconclusive due to methodological differences [13]. In a large cohort of German NHRs, we recently found that hospitalisation rates declined with increasing age even up to $95+$ years, but this effect was much more pronounced before nursing home entry [33]. These inconsistent findings on the influence of age in the literature may be on the one hand due to different outcomes. Two of the studies included in our review assessed prevalences [14, 24] and one assessed incidences [15] of ED visits. The included studies also used different statistical analyses (e.g., logistic, poisson or cox proportional hazard regression). On the other hand, age 
was mostly assessed as a continuous variable in regression models, although no linear effect might exist, or with only few categories. Three out of seven studies included in this review conducted multivariable analyses including age as a continuous variable $[18,22,23]$ and the other four studies used $85+$ or $86+$ years as the highest age category $[14,15,24,25]$. As NHRs typically represent a much wider age span ranging between under 65 up to over 100 years [10, 11], more differentiated age-specific patterns have to be assessed. When further taking into account that women have longer life expectancies than men resulting in a higher percentage of women at older ages [10], both sociodemographic variables have to be considered simultaneously. This is important because the individual effects of age and sex cannot be determined otherwise and confounding or effect modification is possible. However, none of the included studies stratified their results on ED visits by age and sex.

In our recent systematic review on age and sex differences in hospitalisations of NHR, we encouraged further research on the influence of sociodemographic characteristics on ED visits of NHRs [13]. As ED visits are frequent events in NHRs and only about half of the visits result in hospital admission [1, 9, 23], acute care in EDs plays an important role. Interestingly, we only found seven studies (of which the two articles from Stephens et al. even reported findings from the same study $[24,25]$ ) on age or sex differences in ED visits of NHRs as compared to 20 in our review on hospitalisations [13]. Moore et al. already pointed out in 2012 [10], that understanding age and sex dependent patterns in NHRs is the key to optimize individual care. Therefore, we strongly encourage that any further research on health care of NHRs should include large sample sizes and consider differences between these sociodemographic characteristics. Only after exploring reasons for age and sex specific patterns of ED visits, conclusions for health administrators and clinicians can be drawn.

\section{Strengths and limitations}

We conducted the first systematic review examining age and sex differences in the epidemiology of ED visits of NHRs using a comprehensive search strategy. We did not restrict our search to specific languages. Furthermore, we screened reference lists of all included articles. Nevertheless, there is still the possibility that we could have missed studies that comprised information about ED visits of NHRs by sex or age. However, we screened the full text of about 100 articles that might have reported such information but finally included only seven relevant studies in our systematic review. The interpretation of our findings is limited by the inclusion of very heterogeneous studies in terms of populations, time frames and estimates (e.g. crude or standardised frequencies and multivariable regression models) which might have accounted for some of the differences in the results. The studies included are also too few to assess time trends or differences between countries.

Since there are no established and validated tools for studies on prevalence and incidence, quality assessment was carried out by using the critical appraisal instrument of the JBI [21]. This tool rather gives an overview on the study characteristics than evaluating methodological quality and the application to studies using administrative data is difficult because they generally have, for example, an adequate response or an appropriate sample size. Further research on tools for quality assessment of studies examining prevalences or incidences is needed.

\section{Conclusion}

Our knowledge on age and sex differences in acute care use of NHRs is still limited. We only found seven studies meeting our inclusion criteria. Male NHRs visit EDs more often than females, but reasons for that are not analysed or discussed in the corresponding studies. The influence of age is less clear, which might be due to very heterogeneous age categorisations. Taken together, any future studies on acute care of NHRs should assess the influence of sociodemographic characteristics like age and sex. These studies should include large sample sizes to provide a more differentiated age categorisation.

\section{Additional file}

Additional file 1: Search strategy. (DOCX $15 \mathrm{~kb}$ )

\section{Abbreviations}

ED: Emergency department; JBI: Joanna Briggs Institute; NH: Nursing home; NHR: Nursing home resident; OR: Odds Ratio; RN: Registered nurses

\section{Funding}

This research received no specific grant from any funding agency in the public, commercial or non-profit sectors.

\section{Availability of data and materials}

All data generated or analysed during this study are included in this published article [and its supplementary information files].

\section{Authors' contributions \\ $A B, F H$ and KA developed the concept of this systematic review. Then a comprehensive search strategy was generated by $A B$ and tested by $A B$ and $K A$. $A B$ performed the literature search. $A B, F H$ and $K A$ participated in the selection of literature, in the data extraction and quality assessment. All authors participated in the analysis of the literature, wrote and reviewed the manuscript and approved the final version.}

Ethics approval and consent to participate Not applicable.

Consent for publication

Not applicable. 


\section{Competing interests}

The authors declare that they have no competing interests.

\section{Publisher's Note}

Springer Nature remains neutral with regard to jurisdictional claims in published maps and institutional affiliations.

\section{Author details}

${ }^{1}$ Department 11 Human and Health Sciences, University Bremen, Bremen, Germany. ${ }^{2}$ Department of Health Services Research, Carl von Ossietzky University Oldenburg, Oldenburg, Germany.

Received: 3 April 2018 Accepted: 26 June 2018

Published online: 03 July 2018

\section{References}

1. Gruneir A, Silver MJ, Rochon PA. Emergency department use by older adults: a literature review on trends, appropriateness, and consequences of unmet health care needs. Med Care Res Rev. 2011:68:131-55.

2. U.S. Department of Health \& Human Services (HHS). Nursing Home Data Compendium 2015 Edition. [cited 2018 Jan 22]. Available from: https://www.cms.gov/Medicare/Provider-Enrollment-and-Certification/ CertificationandComplianc/Downloads/nursinghomedatacompendium_ 508-2015.pdf

3. Wofford JL, Schwartz E, Byrum JE. The role of emergency services in health care for the elderly: a review. J Emerg Med. 1993;11:317-26.

4. Gruneir A, Bronskill SE, Newman A, Bell CM, Gozdyra P, Anderson GM, et al. Variation in emergency department transfer rates from nursing homes in Ontario, Canada. Healthc Policy. 2016;12:76-88.

5. Renom-Guiteras A, Uhrenfeldt L, Meyer G, Mann E. Assessment tools for determining appropriateness of admission to acute care of persons transferred from long-term care facilities: a systematic review. BMC Geriatr. 2014;14:80.

6. Dwyer R, Gabbe B, Stoelwinder JU, Lowthian J. A systematic review of outcomes following emergency transfer to hospital for residents of aged care facilities. Age Ageing. 2014:43:759-66.

7. Arendts G, Howard K. The interface between residential aged care and the emergency department: a systematic review. Age Ageing. 2010;39:306-12.

8. Gruneir A, Bell CM, Bronskill SE, Schull M, Anderson GM, Rochon PA. Frequency and pattern of emergency department visits by long-term care residents-a population-based study. J Am Geriatr Soc. 2010;58:510-7.

9. Burke RE, Rooks SP, Levy C, Schwartz R, Ginde AA. Identifying potentially preventable emergency department visits by nursing home residents in the United States. J Am Med Dir Assoc. 2015;16:395-9.

10. Moore KL, Boscardin WJ, Steinman MA, Schwartz JB. Age and sex variation in prevalence of chronic medical conditions in older residents of U.S. nursing homes. J Am Geriatr Soc. 2012;60:756-64.

11. Hoffmann F, Boeschen D, Dörks M, Herget-Rosenthal S, Petersen J, Schmiemann G. Renal insufficiency and medication in nursing home residents. Dtsch Ärzteblatt Int. 2016;113:92-8.

12. Moore KL, Boscardin WJ, Steinman MA, Schwartz JB. Patterns of chronic co-morbid medical conditions in older residents of U.S. nursing homes: differences between the sexes and across the agespan. J Nutr Health Aging. 2014;18:429-36.

13. Hoffmann F, Allers K. Age and sex differences in hospitalisation of nursing home residents: a systematic review. BMJ Open. 2016;6:e011912.

14. Kihlgren A, Wimo A, Mamhidir A-G. Older patients referred by community nurses to emergency departments-a descriptive cross-sectional follow-up study in a Swedish context. Scand J Caring Sci. 2014;28:97-103.

15. Hsiao C-J, Hing E. Emergency department visits and resulting hospitalizations by elderly nursing home residents, 2001-2008. Res Aging. 2014:36:207-27.

16. Castle NG, Mor V. Hospitalization of nursing home residents: a review of the literature, 1980-1995. Med Care Res Rev. 1996;53:123-48

17. Grabowski DC, Stewart KA, Broderick SM, Coots LA. Predictors of nursing home hospitalization: a review of the literature. Med Care Res Rev. 2008;65:3-39.

18. McGregor MJ, Abu-Laban RB, Ronald LA, McGrail KM, Andrusiek D, Baumbusch J, et al. Nursing home characteristics associated with resident transfers to emergency departments. Can J Aging. 2014;33:38-48.
19. Kung J, Campbell S. A Filter to Retrieve Studies related to Emergency Departments from the EMBASE Database. John W. Scott Health Sciences Library, University of Alberta. January 20, 2015 [cited 2018 Jan 16]. Available from: https://era.library.ualberta.ca/items/81ea6d08-1ba6-4a57-b45c3fc13c908d36/view/4ad26506-e0ea-4cbc-9873-e37e469ceee6/Emergency_ Dept_EMBASE_Jan_20_2015.pdf.

20. Albert M, McCaig LF, Ashman JJ. Emergency department visits by persons aged 65 and over: United States, 2009-2010. NCHS Data Brief; 2013. p. 1-8.

21. Munn Z, Moola S, Lisy K, Riitano D, Tufanaru C. Methodological guidance for systematic reviews of observational epidemiological studies reporting prevalence and cumulative incidence data. Int J Evid Based Healthc. 2015;13:147-53

22. Ackermann RJ, Kemle KA, Vogel RL, Griffin RC. Emergency department use by nursing home residents. Ann Emerg Med. 1998;31:749-57.

23. LaMantia MA, Lane KA, Tu W, Carnahan JL, Messina F, Unroe KT. Patterns of emergency department use among long-stay nursing home residents with differing levels of dementia severity. J Am Med Dir Assoc. 2016;17:541-6.

24. Stephens CE, Newcomer R, Blegen M, Miller B, Harrington C. Emergency department use by nursing home residents: effect of severity of cognitive impairment. Gerontologist. 2012;52:383-93.

25. Stephens CE, Newcomer R, Blegen M, Miller B, Harrington C. The effects of cognitive impairment on nursing home residents' emergency department visits and hospitalizations. Alzheimers Dement. 2014;10:835-43.

26. Latham LP, Ackroyd-Stolarz S. Emergency department utilization by older adults: a descriptive study. Can Geriatr J. 2014;17:118-25.

27. Trahan LM, Spiers JA, Cummings GG. Decisions to transfer nursing home residents to emergency departments: a scoping review of contributing factors and staff perspectives. J Am Med Dir Assoc. 2016;17:994-1005.

28. Caffrey C. Potentially preventable emergency department visits by nursing home residents: United States, 2004. NCHS Data Brief; 2010. p. 1-8.

29. Carter L, Skinner J, Robinson S. Patients from care homes who attend the emergency department: could they be managed differently. Emerg Med J. 2009:26:259-62.

30. Ouslander JG, Lamb G, Tappen R, Herndon L, Diaz S, Roos BA, et al. Interventions to reduce hospitalizations from nursing homes: evaluation of the INTERACT II collaborative quality improvement project. J Am Geriatr Soc. 2011:59:745-53.

31. Keskinoğlu P, İnan F. Analysis of emergency department visits by elderly patients in an urban public hospital in Turkey. J Clin Gerontol Geriatr. 2014;5:127-31. No longer published by Elsevier

32. Huang J-A, Hu W-H, Yang D-Y, Weng R-H, Tsai W-C. Analysis of emergency department utilization by elderly patients under National Health Insurance. Kaohsiung J Med Sci. 2003;19:113-9.

33. Hoffmann F, Allers K. Variations over time in the effects of age and sex on hospitalization rates before and after admission to a nursing home: a German cohort study. Maturitas. 2017:102:50-5.

\section{Ready to submit your research? Choose BMC and benefit from:}

- fast, convenient online submission

- thorough peer review by experienced researchers in your field

- rapid publication on acceptance

- support for research data, including large and complex data types

- gold Open Access which fosters wider collaboration and increased citations

- maximum visibility for your research: over $100 \mathrm{M}$ website views per year

At BMC, research is always in progress.

Learn more biomedcentral.com/submissions 